Article

\title{
Motivations and Attitudes: An Empirical Study on DIY (Do-It-Yourself) Consumers in Hungary
}

\author{
Anikó Khademi-Vidra ${ }^{1, *}$ and Zoltán Bujdosó ${ }^{2}$ \\ 1 Enyedi György Doctoral School of Regional Sciences, Szent István University, 2100 Gödöllő, Hungary \\ 2 Department of Marketing and Catering, Eszterházy Károly University, 3200 Gyöngyös, Hungary; \\ bujdoso.zoltan@uni-eszterhazy.hu \\ * Correspondence: Khademi.Vidra.Aniko@gtk.szie.hu
}

Received: 7 November 2019; Accepted: 4 January 2020; Published: 9 January 2020

\begin{abstract}
The market for homemade and handcrafted items has expanded significantly in recent years. Related activities range from community-supported agricultural activities, tinkering at home, renovating our houses, design elements, and defining space in the world of gastronomy and fashion as well, and it extends to cover many other activities, where the "producers" also double up as the consumers. The number of scientific analyses in Hungarian language dealing with this subject is very low and no deep empirical results (interviews, questionnaires, ethnographic analyses, etc.) to support our scientific experience exist yet. The purpose of this study is first to review the terminology issued and difficulties that are related to this phenomenon, and, based on the results of a questionnaire survey, and secondly to explore the motivations of DIYers and the attitudes behind their actions. In our study, we mean on Do-It-Yourself (DIY)—in line with the vast majority of literature-all activities, services, and products, which is implemented by own hands not under industrial circumstences. The target group of the online questionnaire survey was the people that are involved in DIY. The questionnaire was shared by a decorator and her DIY Facebook page ("Juditu") on 3 October 2017. The size of the relevant sample was 270. The research questionnaire was built up from a demographic part, a part that is related to general DIY activity, and a part that sought to find the motivation of DIY members. The practice of DIY activities might be linked more to the personality and creativity; so, the group can be more homogeneously described along the common personality traits than by demographic variables. Among the motivations of DIYers the economic one (saving money) is not the most dominant. Analyses by interpretative index categories confirmed the hypothesis that it is difficult to separate one motivational force from the other; in many cases, one catalysing force generates the other, thus a complex multifactorial motivational set dominates the study target group. From the three groups, which were identified by analysing the motivations, in two groups those individuals are dominant, which use DIY activities to express their own inner world, and for whom spending time creatively, making something alone and for themselves, and creating something useful and valuable, is very important. These results were novel and, naturally, they can be perfect starting points of further studies because of the intactness of the research topic.
\end{abstract}

Keywords: consumption; identity; lifestyle; handicraft culture; DIY

\section{Introduction}

\subsection{The Symbolism of Consumption}

In the 1970s and 80s, the theories that were related to consumer society postulated the theorem that new and growing consumer demand were one of the most important reasons for the dynamism of the economic phenomenon, known as the Industrial Revolution and the emergence of mass society. 
According to Pierre Bourdieu [1], "the specific economic differences double by the way the commodities are used or, in other words, by differences in consumption, and even more in symbolic consumption. Symbolic consumption transforms goods into signs, transforms differences of fact into meaningful differentiation or values, preferring the appearance and form of actions or objects over their functions. It assigns value to the differences by attributing greater importance to the mode, activity, or the object's form than to its function. Consequently, those differences are the most prestigious, which symbolize the place that is occupied by the consumer in the social structure" [1]. Baudrillard describes consumption in a similar manner; he regards it as a conscious social expression. He believes that consumption is the virtual sum of all objects and messages that are thus more or less transformed into "spoken words". Consumption, whenever it has meaning, therefore, becomes the activity of signal manipulation [2].

At the same time, consumption can be interpreted as a culture by the expression of the value system and the ethics [3]. Consumers buy not only commodities, but also accept patterns of choice and happiness that are relayed by advertisements. Individuals are encouraged to find the key to their personal well-being in commodities, and they perceive even their own self as a commodity. People can sell not only their labor and knowledge, but also their self-image as personality $[4,5]$. The above-described consumer theories and thoughts are closely related to each other, with the main themes pointing towards consumer activity, which, as an increasingly dynamic means of self-expression, becomes a symbol of varying quality (whether positive or negative). These phenomena are associated with a certain group of consumers who are eagerly looking for experiences. In Schulze's Experience Society, entertainment became a stand-alone industry, and the media realized that its most powerful potential is not to satisfy a person's desire for experience-but to create and nourish it permanently. In the context of the consumer activities that are associated with symbolic consumption, therefore, it is necessary to distinguish craftsmen acting "encouraged by the presence of real values" from the people who want only to be part of a "trendy" Do-It-Yourself (DIY) group, even in the case of present study, which symbolizes something different and larger than their real selves. This difference must be reflected by the sociological concept most related to our study [6].

The lifestyle test examines "the activities selected under given social conditions and relative freedom, and places the preferences related to them as the focus of its investigations" [7]. Lifestyle is part of the way of life and consumer activity is the result of lifestyle and "free choices" set by one's financial situation. This free choices reflects the individual's taste, preference, and value perspective, but can be compromised by free choices, circumstances, and specific situations. A DIY activity involves self-expression and self-realization, but, in many cases, the primary motivation is simple economic, driven by cost-cutting intentions and other motivations are only secondary, when starting such an activity.

Of course, not only DIY products or services can give satisfaction or self-sufficiency for consumers. Industrial products could also fulfil the requirements of complacency, like large quantity and timely delivery or high quality and environmentally friendly production. Industrial product manufacturers can also provide customisation according to the specific needs of customers (like product labelling or packaging) or excellent customer service and technical support. The difference are on the focus of the before-mentioned motivations and lifestyle [8].

No matter the interpretation of the handcraft culture, it is getting increasingly popular, gaining more ground. DIY and self-service consumer markets are growing steadily [9]. In 2013, the value of the global DIY market was 31,9 billion UDS and 2018 reached 43,7 billion USD [10]. In Hungary, the sales of DIY materials have increased over the six-year period, with 2017 producing approximately 83.9 billion HUF ( 280,000USD) in sales for the sector [11]. The first international DIY store appeared in Hungarian market 34 years ago. The leading DIY retailers in Hungary are currently Bauhaus, OBI, Praktiker, and IKEA. The target groups of DIY stores in Hungary are various. The first, which takes $75 \%$ of sales, are called "home creators" who look for solutions to their renovation, decoration, and building problems, and they are open to carry out the implementation themselves either for financial 
barriers or creativity reasons. This group is the main target of the marketing activity of all DIY market chains, as they are the followers of "you can do it with us" concept.

The second target group whose hoppy is DIY are interested in all technical novelties and they prefer to buy the newest tools or facilities for hobby activities. Men mainly represent this group and it accounts for approximately $10-15 \%$ of total sales.

The smallest group is professionals who mainly make their purchases from wholesalers or directly from the factory. They visit DIY stores only occasionally, when they suddenly run out of a material [12].

The description and understanding of these types of activities, processes, and subcultures are also aimed at understanding the microcosm of the present consumer world, which can be part of the combination of real value creation and "over-consumption". In our opinion, motivational power, which causes action, has a strong catalytic role and if these positive, dynamic processes are interpreted in scientific research, they can shift the young generations" "passive culture" towards activity.

\subsection{Possible Definitions for the DIY Concept}

It was mentioned in the previous chapter that there are many processes in progress nowadays, through which valuable and useful sociological and social psychological interpretations could be formulated about consumers. Mostly the English language literature deals with handicraft culture and with the description of the DIY type activities; in Hungarian literature regarding sociology of consumption, we do not really find definitions, limited and differentiated interpretations of concepts. During a superficial examination of concepts, we might mention expressions with synonymous meaning, but we can perceive the shaded differences and the different attributes with a deeper understanding.

The term "DO-IT-YOURSELF" appeared in 1912 for the first time in literature [13] and primarily referred to activities carried out by non-professional practitioners involved in home improvement and maintenance [14]. Wolf and McQuitty [15] define DIY as an activity in which the individual creates, composes, recreates, or rebuilds objects while using non-processed or semi-processed materials. In DIY activities the self-sufficiency, craftsmanship, freely chosen simple naturalness are the most important aspects. According to Bateson [16] and Dabholkar [17], self-sufficiency can be described as a DIY behaviour, but DIY is characterized by greater self-sufficiency. With self-sufficiency, the customer's waiting time is shortened, the service provider is relieved of the delivery tasks, and the consumer can access to products and services cheaper and more conveniently. At the same time, DIY activities require more effort from the consumer and they are not necessarily dependent on costs. If we compare them with craftsmanship, we can conclude that the creation of handcrafted produces requires more resources and more invested work [15]. The "mission" of both craftsmanship and volunteered naturalness aims to circumvent the traditional markets, to keep processes under control, and to try to disengage from the institutional systems of commerce, to some extent. Besides the rational, economic motivations described above, there are many reasons why the consumer starts doing DIY activities: spending free time in a useful and creative way, the feeling of success after a well-executed project, or perhaps a sense of self-identity can also catalyze the consumer. The research findings of Wolf and McQuitty [18] have shown that individuals who start DIY activities consider the market as a medium that determines for the consumer which products to produce for themselves and which are the ones that they need to buy. If the goods prove to be too expensive, inadequate, or unavailable for some reason in market conditions, then consumers have to produce them themselves. Thus, market conditions, the structure, and distribution of the consumer market have great influence on the actions of people with certain behaviour marks. The lack of goods, the low quality of services or limited access to the products and services are common causes; however, we do not exclude other possible causes, such as having fun during working or expressing one's [15].

In conclusion, we can say that the boundary of DIY is very flexible, in our study we mean on DIY-in line with the vast majority of literature-all activities, services, and products, which is implemented by own hands not under industrial circumstances $[19,20]$. 


\section{Motivation Analyses, Approaches}

Theoretical scientific works on the motivations of DIY activities describe two approaches. In one of the approaches, which is actually a pragmatic interpretation of processes, DIY activity is a process that results from an economic motivation that the consumer needs to do or the consumer chooses to accomplish. In the other view, consumption is interpreted in a more abstract, theoretical plane, contradicting each other at least three times. The first "mode" considers DIY activity as a rational and necessary choice; in this reading, the added value of one's home can be increased by performing workflows. The examination of Brodersen [21] in Denmark reveals that DIYs consider their houses, apartments, and premises as business investments; they are also committed to active actions and renovations while also naturally calculating the payback period of their costs. By contrast, Littlewood and Munro's 1996 survey argued that the primary motivation of people that are involved in DIY activities is not to increase the market value of the property, but rather the comfort of living space [22]. Interpretations in the second group report that, in many cases, the DIYers is an impressionable person that is influenced by the media, whose "anxiety" of this type is highly assisted by retailers.

In the recent past, popular media content, blogs, TV shows, Facebook groups, and Pinterest's endless ideas provoked faded excitements in humans [23]. In many cases, people are responding to pressure from society: be "special" or "unique". Additionally, although not necessarily everyone wants to be unique, the membership requirement is in fact uniqueness or at least looking unique. This interpretation, therefore, focuses on the manipulation and the maintenance of social illusion. The third subtype of the theoretical aspect emphasizes the symbolic expression of identity [24,25]. Research by Woodward [26] shows that, in many cases, home is a symbol of aesthetic idealism and DIY enthusiasts often realize themselves or the image they desire-using their home and apartment as a tool [27]. The approaches that are outlined above are empirically justified, but their occurrence, in the uniform manner described, is not really lifelike. The current research opines that a differentiated, complex, and mixed motivational set characterizes the DIY group of people, who, based on these motivations, can be discussed as a homogeneous group by their demographic characteristics at best. Earlier analyses of people that are involved in DIY focused more on the distribution of income relationships behind economic motivation, and not as much on the fact that, in many cases, complementary, hypothesized, and interlinked economic and recreational motives are difficult to distinguish.

\subsection{Characterising the Handicraft Culture}

The meaning of the concept of "craft culture" in the Hungarian and English languages is not similar: in the Hungarian language, craftsmanship, and culture is primarily organized around nutrition and folk craftsmen, and its only in recent years that the concept's semantic range has been observed to be widening. Nowadays, this concept embraces a broad spectrum of activities related to lifestyle, in which, the marks of human (often consumer) handwork can be found to some extent and in certain quality. Colin Campbell [28] describes handicraft culture in detail, the author presents artisanal activity as not an unconscious, undemanding, passive work process, but as a series of actions that creates an artwork from a lifeless object by giving it a new meaning [29]. The action itself is about not only possession, but style and ritual. Craftwork is a cultural practice in which the mode is greatly emphasized. The creators participate in production and consumption with their full personality; they are present not in an excluded, controlling manner; they are not outsiders in the consumption process, but they are moved by their emotions and knowledge towards the activity.

The essence of the definition of Campbell can be summarised, as follows: first, it is an authentic process and, due to its creative aspect, it is very close to human nature and it reflects the traditions, rituals, and their reintegration (criticism of the virtual world, both from an individual and a social point of view). Secondly, the basis for this activity is the exploitation of creativity and playfulness. In addition, the individual (mostly) uses a set of manual skills to initiate an activity, which he or she is the creator of, but its user is somebody else or the creator is also the user. In the latter case, the personal control of the consumer is continuous. Further to these, the possession (and nurturing) also has a 
ritual; in order for someone to feel the object, the objects must assimilate to their environment that is; personalisation (the intention of object personalization is observable, and the consumer can choose, decide, and plan, and it can imbue its own personality into the object), customization, and subversive customization. The experience of personality, in the case selling also occurs, depends on the experience of the receiver (if the creator and the consumer are the same person, the sense of personality is natural) and, lastly, that handcrafting can also be mass production [28].

Social Critical Attitudes Regarding Craftsmanship

In Pierre Bourdieu's opinion, the presence of cultural capital is a guarantee of the authentic expression of self-realization. The presence of cultural capital forms the style and the value perspective. Cultural capital is a tool in the process, in which an enthusiastic, active consumer fights the homogenization of alienating mass culture [30,31]. Why is this phenomenon popular today? On the one hand, handcrafting is a very powerful social criticism that the artist can outweigh a lot of things. In many cases, it is the "compensation" of reality, as there is a growing demand for an own, personal, controllable processes. The creative process offers a range of possibilities, which also serve as tools. The products are embodiments of the value that is added by the individual, and it is expressed with sincerity, and the process creates the consumer's own "oasis", in which "the green life" is their own personality without any kind of mask, without the expectation and fake role interpretations. The activity generates its market for itself [32], and it functions as a hobby, a recreational, renewable resource that is completely different than the world of work. Surveys show that the active participants of craft culture are primarily middle-class and educated individuals who are experiencing a de-professionalization process in their workplace, due to the growing bureaucracy and lack of competence and systemic approach.

In other words, work does not bring the expected values and experiences to the people. As a result, people are retreating into a world based on their own mindset and self-expression, where, according to their own rules, there is an infinite number of independent and creative ways of expression. If the world is not suitable for them, they will actively create it for themselves. This social group has a strong sense of duty and can create a distinctive cultural value through their own value sets and traditions, based upon their taste, sense of beauty, authenticity, freedom, and personal expression [28], or their illusion.

DIY activities also have meaning in terms of sustainability. On the one hand, DIY activities contribute to social sustainability with traditionalism. Open workshops provide the possibility of presenting the former professions for current audience. As for economic sustainability, DIY improves the local employment and gives opportunity for additional source of income contributing to the welfare of local community. As far as environmental sustainability is concerned, DIY helps in the reusing of waste, rest, and byproducts.

\section{Materials and Methods}

The following hypotheses were set for the research:

Hypothesis 1 (H1). The group of DIYers can be described along demographic variables as a homogeneous group.

Hypothesis 2 (H2). Among the motivations of DIYers the economic one (saving money) is not the most dominant.

Hypothesis 3 (H3). The motivations behind the activities of the DIYers can be characterised as a complex motivational set, in which the individual motivation types are difficult to distinguish, and they complement each other, being related to different fields of life (such as the material sphere, recreation and personality). 
Hypothesis 4 (H4). Within the group of DIYers, those individuals will be the majority, who use the activity to express their own inner world, and it is very important for them to make a useful product by themselves, in creative ways.

The H1 hypothesis was created due to none of the existing research demographically describing the target group. Significant research deals with the motivational set, the description of the activity itself, or its symbolic meanings. It is not clear whether they refer to homogeneous or differentiated groups. Based on the DIY communities' presence in social media, other virtual platforms, and offline Hungarian media, the research assumed that these demographic variables would have similar distribution amongst the study population.

The objective of the H2 hypothesis is to refute Brodersen's [21] Danish study, because the hypothesis (H2) of the current study is that economic motivation cannot be emphasized, even though it might be important in saving money, but it is not the most important catalyst of DIY motivation. The three main directions that are described in the theory [21,23-25] cannot be isolated, they are not independent completely in each DIY activity, but they are present rather in a blended, intertwined, and complementary way (H3). In this regard, the current study assumes (H4) that the DYI subculture can be characterized and described with the help of Campbell's [28] theory: a creative authentic process in which the need for personalization is coupled with the love of creation.

The target group of the online questionnaire survey were the people involved in DIY. During the sampling, the research sought to find easy-to-reach subjects, so the most obvious one was to reach a test population, which—in any way-would certainly be connected to DIY. Accordingly, a decorator and her DIY Facebook page shared the questionnaire ("Juditu") on 3 October 2017. The site has 28,682 likes and it plays a major role in Hungarian DIY culture. We mainly come across home design and home DIY solutions on the site and related blog. Judit Varga as a DIY blogger for home decor has been running this site for almost 10 years. The demographics of the site's visitors are well represented by the sample. While $71 \%$ of the respondents are women with a university degree $(96 \%)$, the pattern is heterogeneous in terms of occupation and income situation. The size of the relevant sample was 270 . The research questionnaire consisting of 16 questions and containing mostly closed questions was built up from a demographic part, a part related to general DIY activity, and a part that sought to find the motivation of DIY members (Table 1).

Table 1. Parameters of the questionnaire survey $(n=270)$.

\begin{tabular}{cc}
\hline Questionnaire Questions \\
Demographic part & $\begin{array}{c}\text { Gender } \\
\text { Age }\end{array}$ \\
Highest level of education \\
Current occupation, work activity \\
Number of persons living in the household \\
Net income
\end{tabular}

The questionnaire's demographical questions focused on the characteristics general variables that describe the DIYers and they were aimed at supporting or rejecting the H1 hypothesis. The research tried to operationalize the studies of Wolf and McQuitty [16] and endeavored to obtain an overview 
on what a DYI activity is; what the respondents meant by DIY and what types of activities were associated with the phenomenon. The research employed a set of questions on theoretical literatures, such as Crewe [24], Dowling [25], Woodward [26], or Clarke [27], etc., which emphasized economy, practicality, and consumerism as dummies to DIY to study the motivation behind the DIY activity. The operationalization of Campbell's theory was carried out in the other half of the questions. The authentic study of this community, mostly through social media channels, has been going on for a long time, so independent questions from the observations were included in the questionnaire.

The research used the IBM SPSS Statistics 20 to process the questionnaire database. The descriptive statistics (frequency, average, standard deviation) were used for a general evaluation of the questionnaire, while cross-tabulation analysis was employed in exploring deeper relationships and testing the first two hypotheses $(\mathrm{H} 1, \mathrm{H} 2)$. The researcher examined how respondents could be characterized as a homogeneous or differentiated group in terms of their demographic characteristics, and the type of motivations behind the phenomenon of DIY activity. The relationship between the variables (demographic issues, closed questions) was tested with the help of Pearson's Chi-square, and the strength of the relationship was tested with the following association coefficients: Cramer's V, Gamma, etc. The main component and cluster analysis method were used to test the third (H3) and fourth (H4) hypotheses. The research endeavored to identify clusters that are based on the motivations behind the DIY activity and also focused the characteristics and features that the different clusters have. The principle component analysis was used to reduce the number of variables (Table 2) and cluster analysis was performed with the established factors (Table 3). In processing the results, the researcher tried to reveal dependency relationships between the different criteria by using cross-tabulation analysis. Cross-tabulation analysis was also used to identify deeper relationships.

Table 2. Motivations behind Do-It-Yourself (DIY) activities, according to the survey results $(n=270)$.

\begin{tabular}{ccc}
\hline Statement & Average & Dispersion \\
\hline Because it makes me feel satisfied if my work has a successful result & 2.85 & 0.4146 \\
Because I like trying out new things and to learn new skills & 2.84 & 0.4268 \\
Because the success I feel from the object I create and the process itself & 2.76 & 0.4805 \\
inspires to make new things, to do new activities & 2.58 & 0.6285 \\
Because I can create objects the perfect size and style & 2.56 & 0.6189 \\
Because I can express myself through these objects and projects & 2.36 & 0.7785 \\
Because I like to say it to others proudly: "I made it myself" & 2.35 & 0.7563 \\
Because I could not find in the shops what I was looking for & 2.27 & 0.7842 \\
Because I like to challenge my limits & 2.17 & 0.6752 \\
Because this way I can save money & 2.07 & 0.7593 \\
Because this way I can make sure of the quality of the product & 2.07 & 0.8122 \\
Because it is very important for me to create something unique & 2.01 & 0.7870 \\
Because I was inspired by TV shows, Facebook pages and blogs to do & 1.81 & 0.7678 \\
something similar & 1.79 & 0.6509 \\
Because I like to boast to others with my work & 1.46 & 0.6885 \\
Because the products and the work process is of higher quality than what I & 1.44 & 0.6541 \\
can get in the shops & 1.19 & 0.4601
\end{tabular}


Table 3. Main motivations behind DIY activities $(n=270)$.

\begin{tabular}{|c|c|c|c|c|c|c|}
\hline \multicolumn{7}{|c|}{ Rotated Principle Component Matrix } \\
\hline \multirow{2}{*}{$\begin{array}{l}\text { Names of Principle } \\
\text { Component }\end{array}$} & \multirow{2}{*}{ Statements } & \multicolumn{5}{|c|}{ Principle Components } \\
\hline & & 1 & 2 & 3 & 4 & 5 \\
\hline \multirow{4}{*}{$\begin{array}{l}\text { Internal motivation, } \\
\text { self-expression }\end{array}$} & $\begin{array}{c}\text { Because the success I feel from the } \\
\text { object I create and the process itself } \\
\text { inspires to make new things, to do } \\
\text { new activities }\end{array}$ & 0.831 & -0.090 & 0.053 & 0.024 & 0.148 \\
\hline & $\begin{array}{l}\text { Because it makes me feel satisfied if } \\
\text { I my work has a successful result }\end{array}$ & 0.784 & -0.084 & 0.194 & 0.108 & -0.061 \\
\hline & $\begin{array}{l}\text { Because I like trying out new } \\
\text { things and to learn new skills }\end{array}$ & 0.765 & 0.051 & -0.022 & 0.025 & 0.194 \\
\hline & $\begin{array}{l}\text { Because I can express myself } \\
\text { through these objects and projects }\end{array}$ & 0.564 & -0.037 & 0.164 & 0.037 & 0.350 \\
\hline \multirow{4}{*}{$\begin{array}{l}\text { Distrust and } \\
\text { financial reasons }\end{array}$} & $\begin{array}{l}\text { Because I have a bad experience } \\
\text { regarding professionals } \\
\text { (quality, reliability) }\end{array}$ & -0.086 & 0.879 & -0.040 & 0.015 & -0.008 \\
\hline & $\begin{array}{l}\text { Because I could not find a } \\
\text { satisfactory professional }\end{array}$ & -0.145 & 0.831 & 0.070 & -0.009 & -0.097 \\
\hline & $\begin{array}{l}\text { Because the products and the work } \\
\text { process is of higher quality than } \\
\text { what I can get in the shops }\end{array}$ & -0.097 & 0.470 & -0.106 & 0.405 & 0.360 \\
\hline & Because this way I can save money & 0.235 & 0.389 & 0.176 & 0.011 & 0.130 \\
\hline \multirow{4}{*}{$\begin{array}{l}\text { Pride and } \\
\text { following trends }\end{array}$} & $\begin{array}{l}\text { Because I like to boast to others } \\
\text { with my work }\end{array}$ & 0.161 & 0.054 & 0.810 & 0.004 & 0.132 \\
\hline & $\begin{array}{c}\text { Because I was inspired by TV } \\
\text { shows, Facebook pages and blogs } \\
\text { to do something similar }\end{array}$ & 0.034 & 0.053 & 0.732 & -0.141 & -0.006 \\
\hline & $\begin{array}{l}\text { Because I like to say it to others } \\
\text { proudly: "I made it myself" }\end{array}$ & 0.407 & 0.027 & 0.635 & 0.183 & -0.063 \\
\hline & Because it is popular & -0.429 & -0.126 & 0.543 & -0.006 & 0.321 \\
\hline \multirow[t]{2}{*}{ Customization } & $\begin{array}{l}\text { Because I could not find in the } \\
\text { shops what I was looking for }\end{array}$ & -0.018 & -0.067 & 0.013 & 0.880 & 0.090 \\
\hline & $\begin{array}{l}\text { Because I can create objects the } \\
\text { perfect size and style }\end{array}$ & 0.204 & 0.130 & -0.017 & 0.814 & -0.048 \\
\hline \multirow{3}{*}{$\begin{array}{l}\text { Challenge, uniqueness } \\
\text { and quality assurance }\end{array}$} & $\begin{array}{l}\text { Because I like to challenge my } \\
\text { limits }\end{array}$ & 0.248 & 0.077 & 0.023 & -0.163 & 0.771 \\
\hline & $\begin{array}{l}\text { Because it is very important for me } \\
\text { to create something unique }\end{array}$ & 0.129 & -0.047 & 0.196 & 0.180 & 0.703 \\
\hline & $\begin{array}{l}\text { Because this way I can make sure } \\
\text { of the quality of the product }\end{array}$ & 0.074 & 0.430 & -0.165 & 0.349 & 0.467 \\
\hline
\end{tabular}

Principle component analyses with Varimax rotation $(\mathrm{KMO}=0.667$; explained variance $62.4 \%)$

Source: [33].

The variables were organized into factors along the conditions provided by the correlation matrix, Anti-image matrix, Measure of Sampling Adequacy, Kaiser-Meyer-Olkin Measure of Sampling Criterion, and Bartlett's Test of Sphericity. For the rotation of the factor weight matrix, the Varimax rotation was used, and the K-centre method was used for cluster analysis [34]. In the analysis of open questions, in accordance with the methodology of qualitative research [35], the research first made the qualitative data grouping and arrangement. The basis for the grouping and the criteria of 
the comparison were, on the one hand, the hypotheses; on the other hand, the index categories, by which the research applied to either confirm or reject research assumptions. The interpretative index categories, which were created from the researcher's point of view, were used to help index the data, and analyze with the same filter, due to the identical reference content.

\section{Results}

\subsection{Examining the Sample}

\subsubsection{Basic Distributions}

The number of respondents was 277, of which the number of relevant responses was $270.96 \%$ of respondents are women, one-third of whom are mothers staying at home with their children. Figure 1 shows the age distribution of the sample:

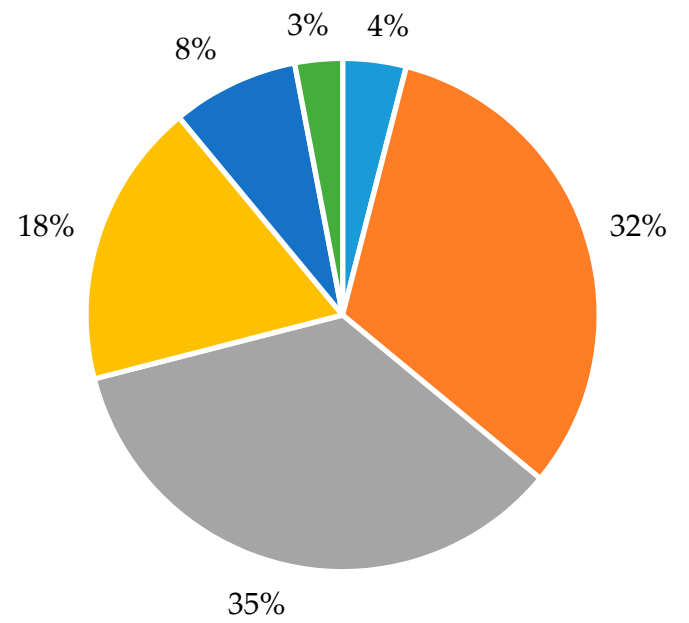

$$
\begin{aligned}
& =\text { Under } 20 \text { years } \\
& =21-30 \\
& =31-40 \\
& =41-50 \\
& =51-60 \\
& =\text { Over } 61 \text { years }
\end{aligned}
$$

Figure 1. The distribution of respondents based on age categories $(\%)(n=270)$; Source: [33].

Regarding the age group, nearly one-third of the sample was 31-40 years old and another third of the respondents were between 21 and 30 years. The range of 41 to 50 -year-olds, who account for $18 \%$ of respondents, is also decisive. With respect to the level of education, it can be stated that respondents with a higher education degree $(71 \%)$ were the majority and their DIY activities are very versatile. The researcher was also curious about the current occupation of the respondents and thus included open-ended questions in the questionnaire. A high percentage of the respondents were women, were mothers staying home with children, designers, who carried out some aspect of creative work, but the presence of administrative workers (pharmacy assistant, bank employee, etc.), who do not have many opportunities to use creativity in their daily work, was also significant. Overall, it was clear from the responses that the nature of the work is not really relevant to the characterization of the group; the researcher opines that it might be more dependent on the personality, and with the presence or lack of opportunities for creativity. $90 \%$ of the respondents stated that their living environment, the geographic position of their homes (for example, being in rural or urban areas), and the size of their home towns does not related at all with whether somebody is involved in DIY, or not.

\subsubsection{Characterising the Group}

Before characterising the group, this next section summarises the reasons behind popularity of Judit's DIY Facebook blog page. The site usually provides the followers with different types of information. On the one hand, numerous DIY techniques can be found that encourages visitors to the activity. Good practices help them in the page to orientate visitors and offer them ideas of DIY. Comments and blogs are the field of sharing point of views, programs, experiences, and results. What 
the respondents liked the most in the blog was its creative ideas that inspired people, and that it was easy to understand and follow. Additionally, it contains quality content. Many thought that the blogger had an attractive personality; friendly and credible; the videos have positive messages; and, that the topics dealt with were always fresh and new. The best response to characterise this blog among others was perhaps the following:

"Fine, powder-like, sweet, but not sugary-glazed. Homely, pleasant, and although our style does not match, I like her naturalness and the website's friendly atmosphere. Her ideas are easy to recreate for anyone. Unambiguous and recognizable ..."

The charm of Judit's personality was "outstanding" from the other "bloggers", because although there was a well-defined, sociometrically measurable community relationship formed with regularly visiting reference people, with blogs and other sites (most visitors of her page also follow the following pages: Otthonkommandó, Merci-Ancsa dekor, Kicsi Ház, Térkultúra, Pinterest, Lakbear, Pure Design by Bardoczeva), their undeniable favourite was Judit. One of the reasons for this might be attributed to the fact that this decorator showed a number of interesting videos and encouraged visitors to the activity. Thus, this active group was characterized by a desire to create, and they can be categorized by their activities, as follows in Figure 2. As we mentioned in Section 1.1., target groups of DIY stores in Hungary are various and represented the respondents who answered the questionnaire. $79 \%$ of the were "home creators", who look for solutions to their renovation, decoration, and building problems. A further $16 \%$ accounts for DIYers who are interested in all technical novelties and that prefer to buy the newest tools or facilities for hobby activities. $5 \%$ of respondents are professionals who mainly make their purchases from wholesalers or directly from the factory in occasions.

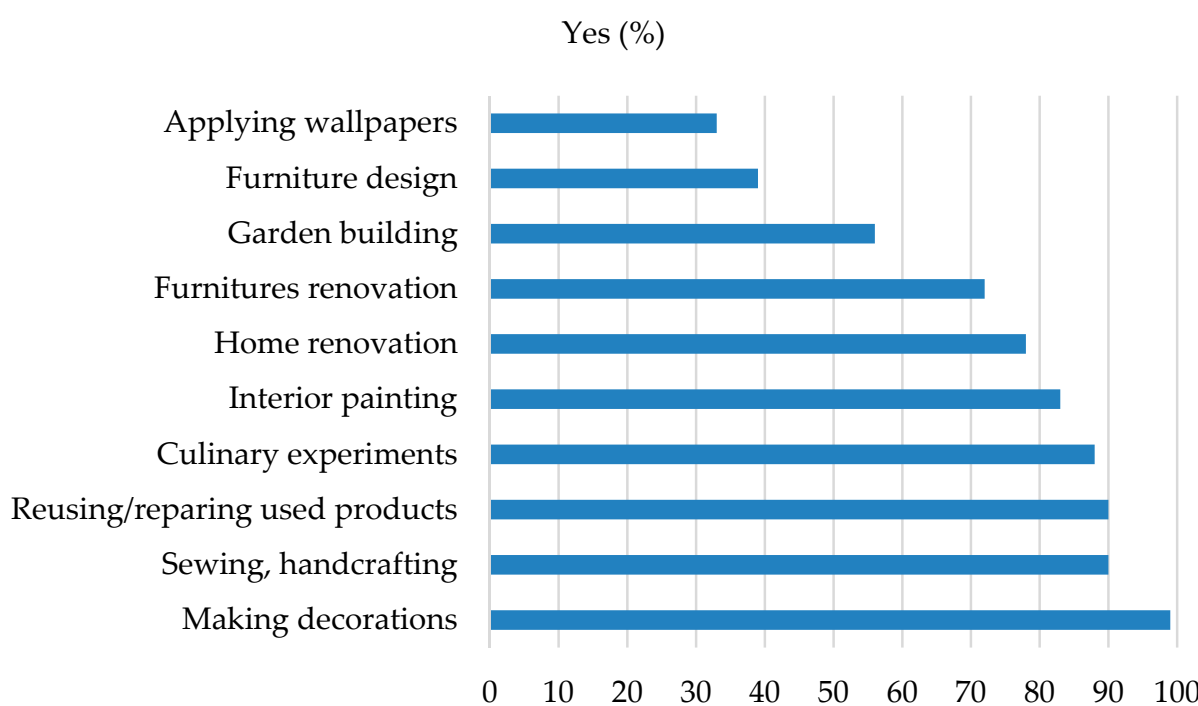

Figure 2. Which activities have you ever done from the following list? (Multiple answers can be chosen!) $(n=270)$; Source: [33].

Practically every respondent has made smaller objects (99\%) and many of them practice a great deal of recycling or handcrafting (90\%). The majority of the participants are keen on culinary experiments and house and furniture renovation (72\%). Gardening was a common answer with more than half $(56 \%)$ of the sample, and one-third of the respondents apply wallpapers (33\%). More difficult tasks around the house $(15 \%)$ and repairing their own cars $(10 \%)$ were not preferred by the respondents.

After discussing the group's opinion leaders and basic activities, it is important when characterizing a group to examine how group members define their activities. The purpose of this question was to explore the activities, values, and qualities that the respondents associate with the DIY concept. When identifying a group's identity, this is one of the most important components. An open-ended 
question was deliberately formulated and the interpretative index categories were used to analyse the answers. The research did not create a category for creativity, because it was assumed as a basic point for such activities. The researcher's assumption was verified by three-quarters of the answers, in different forms, mentioned creativity.

Based on the hypotheses, the following categories were created: focusing the autonomous and unique activity carried out by the individual; process-centric behaviour, the need for self-realisation; reusing; the need for appreciation, personalisation; complex motivations; and, critical attitude, as described in the ensuing paragraphs.

Focusing on the Autonomous and Unique Activity Carried Out by the Individual

From the motivational aspects that were discussed earlier, the third type was the one that appears in the responses as the most dominant one. This direction proves the symbolic expression of the identity [24,25]. The research results can be connected to the findings of Woodward [26] the most, because, in many cases, the home symbolises an aesthetical ideal and DIY enthusiasts very often try to realise their own ideas in their homes [27]:

"What I love best in it is that nobody will have the same advent wreath, painted shelf, cushion, and jewel case like me. If I look at one of the objects, I always remember that I made it myself, so I appreciate it much more than if I bought it in a shop. "

"I'm sure I am making something that cannot be bought in a shop and it feels much better to have something created in your home, than buying it from a shop. I have more pleasure from it. "

"Do-it yourself, which means that the product you create can be yours. So, it is a very unique product that you can love more than what you can get from the market. Plus, spending time in a good way and with a good company. "

"What I love best is that I can make every object with my own hands and knowledge. Everything is my work and everything I make is has my personality in it. "

Process-centric Behaviour, the Need for Self-Realisation

According to Miller [29], handcrafting is not an unconscious, mindless, passive work process, but as a series of actions that creates an artwork from a lifeless object by giving it a new meaning. The action itself is about not only possession, but style, and the ritual itself. The views from the respondents below prove this statement:

"What I like is the process itself, and that when I finish the work, our house becomes decorated. I made something with my own hands. I like spending time on it and the creation process is beautiful."

"Creation is what I like! It feels great creating something myself. (Unfortunately, the object is sometimes prettier in my head than the result ... )"

"I love all of it, starting from gathering inspiration and planning to buying materials and finishing it. The results speak for themselves.)"

The respondents support those theoretical notions, which state that handcrafting is a cultural practice, in which the way, the mode is in focus. The creators also take part with their full personalities in creation and consumption; they are not outsiders, controllers, and they do not only watch things happening from above. Instead, they approach creation with their emotions and knowledge.

"I like ... I the process (the creative process), planning, caring about what you do and the results as well, and the experience, which is to create something physical (unlike in my day job, when it is only virtual). I can touch and hold the result of my work in my hand, and I am happy to use it later" 
"..., that I can create something; I do not only buy something from a shop and that's it, but I make something myself. I put effort in it. By doing so, I do something actively. It is like cycling to work; it is not like travelling on a bus or train, when I just get on it, and passively wait, but actively taking part in getting from point A to point B. DIY is just the same"

"It is an exciting, creative way of expressing myself, which I can do by immersing in it, and which makes the time spent on it interesting. When I look at the result of my work, I feel satisfaction and I can think back about what I felt during the time I made it."

"A creation made by your own hands. This sentence summarises all the reasons behind why I like it."

In terms of emotional manifestations, the word "happiness" expresses best the quality the respondents associate with creation, so much so that it became the most commonly used word:

"Creating is recreation. The result of the work is a source of happiness for me and for others, if I give it to somebody as a gift."

"The happiness during creation. It makes me feel relaxed. I create things for someone else mostly, so the happiness of giving also plays an important role in it."

In addition to the horizons of enjoyment and joy, respondents often mention that, during the activity, one can completely "turn off" the outside world by creating a positive, relaxing, and captivating atmosphere:

"Most importantly, it makes me feel relaxed and I can be creative by it. That fact that I will not see anything similar [ ... to what I make ... ] in my environment motivates me."

"I love using the untapped creative energies inside me and also to create something that reflects my personality; something that is unique and unrepeatable. Creating makes me relaxed, entertained and cheers me up; it can balance out failures of my life."

"Creation makes me feel relaxed and happy."

"Creating, self-expressing, immersion and handcrafting—-these are my natural needs, which I cannot satisfy in my everyday life."

Campbell [28] stated that handcrafting offers a wide range of opportunities as a creative process. Creations express value addition (from the creator or individuals) with honesty and without any falsity:

"Creating through expressing our soul, style; getting to know ourselves as deeply as possible, great recreation opportunity and it is great to see the fruit of my work and my own improvement ... "

"An extension of the self, un- and repacking the self, transformation, creation, fantasy, calmness, giving happiness for others and for myself. Walking away from the everyday life. Self-expression and creativity since I was a child."

These statements show self-reflection and they clearly support that expressing one's identity and self-realisation through various creative ways are perhaps the most important aspects of DIY. As one of the respondents summarised it: " ... the main point of DIY is myself ... "

It was also Campbell [28] who stated that DIY is able to become an important field in the process of de-professionalization, and therefore, a tool: immersion, a meaningful goal and carrying out of tasks can sometimes really make the enthusiasts fly above their "green oasis":

"Whatever I make, I can fully immerse in the process, so it has some kind of therapeutic aspect, and it also improves my handcrafting skills and my aesthetic sense."

"It helps my individual values to surface, and to use my surplus energy to do something useful." 
(Re)using

The need for reusing something appeared in a dominant way in the responses. Actually, it can be concluded that one of the most important attributes was none other than aesthetically or functionally transforming an existing object in a new way and environment, based on the ideas of DIYers. In this case, besides the reinterpretation, the function of usefulness also appears as well, but also the notion of saving money:

"Creativity and endless possibilities. Reusing things, materials, old gadgets. To save old things and to give them new functions."

"Experiencing my own creativity, based on my value set which I developed during my life. We do not throw away what is still useful, or if it cannot be used for its original purpose, we must find new possibilities."

"What I like the best about it is that, on the one hand, very often old and unused things, sometimes waste can be reused as modern decoration, as a useful object; on the other hand, this way I can create objects which are unique and they cannot be found in other people's homes."

"For me it means old objects reborn in new form. Mostly I renovate old furniture, because it is such a good feeling to work on an old and outdated piece of furniture and when I finish I get a new one, so I do not have to throw it out."

The Need for Appreciation, Personalisation

The need for appreciation is related to identity and self-expression. Not predominantly, but as compared to the expected results, many respondents stated that they take pride in creating something, and it is related to the need for appreciation from others:

"I made it with my own hands. I am so happy the get compliments for it, and when they ask me where I bought it)"

"I like it when somebody compliments my work, and then they are surprised to find that it was made by me."

"The result that is admired by everybody...."

When a respondent states that they feel satisfaction by working on their projects, it suggests that their personality is balanced. The DIY object, in this frame of reference, is a very important tool that strengthens positive self-evaluation:

"I like making bigger or smaller things at home. I love tinkering, too. I like it when I can tell about the created object that it was made by me. Either it is for myself, or as a gift."

Campbell [28] states that possessing as well as nurturing something has its own ritual; the object must assimilate to its environment in order for someone to feel that the object belongs to them. Accordingly, customisation (the creator intends to customise the object, and they make the choices, the decision, they design it, and they imbue their own personalities in the object) is a very important part of the creation process, and it is often reflected by the answers of the respondents:

"Realising my own ideas, creating custom objects to fit to my home."

"It means creating my own ideas with my own hands, and to give new "life" to objects."

"I can customise the objects in my flat, based on my own needs, and I can make them unique and they also make me relaxed."

"Do it yourself! I can transform things to my own image." 


\section{Complex Motivations}

Interconnected motivations appeared in many responses, so all of them could practically be highlighted. Here are two examples:

"It makes me feel relaxed and happy to know that I am able to create something new that I like, and I can also save money with it. I can turn the "The Ugly Duckling into the Beautiful Swan".

"If I need something, instead of going to the nearest supermarket, I utilise my own creativity and make that something for myself. Of course, I cannot and do not want to make toilet paper for myself, but if I need a box for example, I can make it from used cardboard. If I want to decorate my flat with new furniture, I try to find an old one for a lower price and I renovate it. It makes me happy that it will become the result of my hands' work, and it is just like how I want it to be, and also I can save money.)"

Critical Voice, Attitude

Critical voices were only a few among the responses. There were only two statements, which support the second group of DIY motivation-related interpretations. This interpretation views the DIY enthusiast as a media-influenced, forced and impressionable person, whose anxiety is further strengthened by retailers [23].

"The expression DIY itself is irritating to me. It is a by-product of a new generation of social media and consumer society that has become so popular, although even in a producer society, the individual himself made/recycled a large part of his possessions, without trying to be "cool", because humans are creator beings; the joy of creation and the desire for creation and the opportunity for development/learning have always been part of man-I love it myself - and a real creative man does not treat their creations as DIY projects. I think the expression itself is the most popular for young people below 40, but it opened up new markets ..."

"I find it funny, that nowadays we call homemade flower plates, painted Easter eggs small things made as school projects as DIY. Furthermore, I do not think it is necessary to use English expression, when we are perfectly capable of expression ourselves in our mother tongue, in Hungarian."

\subsubsection{Motivations, attitudes}

It was a very important element to ask the respondents about the items in Table 2 since the main objective of the study was to explore the motivations. As below, with respective results.

The distribution of responses to the closed questions in the questionnaire contradicted many answers to the open questions about DIY. The highest averages revealed that it is important for the respondents that they feel a satisfaction during the creative process and they can engage in new activities by learning and practicing new skills. The dimensions of self-expression and creation, although emphasized, was not as much compared to the open questions; however, customization showed a very high average for this question when compared to the answers to the open questions. Saving money, social media platform, and patterns relayed from media also appear more significantly during these questions, although it must not be forgotten that the way the questions were asked strongly influenced the content of the answers (e.g., open vs. closed questions).

The 17 variables that were involved in the study were observed to be very suitable for principle component analysis, based on the KMO value (0.667) and the significant Bartlett test. Table 3 indicates the factor structure created, which was the basis of the cluster analysis.

The DIY community was tested by the principle component and cluster analysis can be segmented by the members' motivations. However, it must be noted that these clusters cannot be separated from each other clearly; therefore, differences must be carefully observed. Based on that, three clusters were identified, and their characteristics (based on the principle component analysis) are illustrated in Figure 3. 


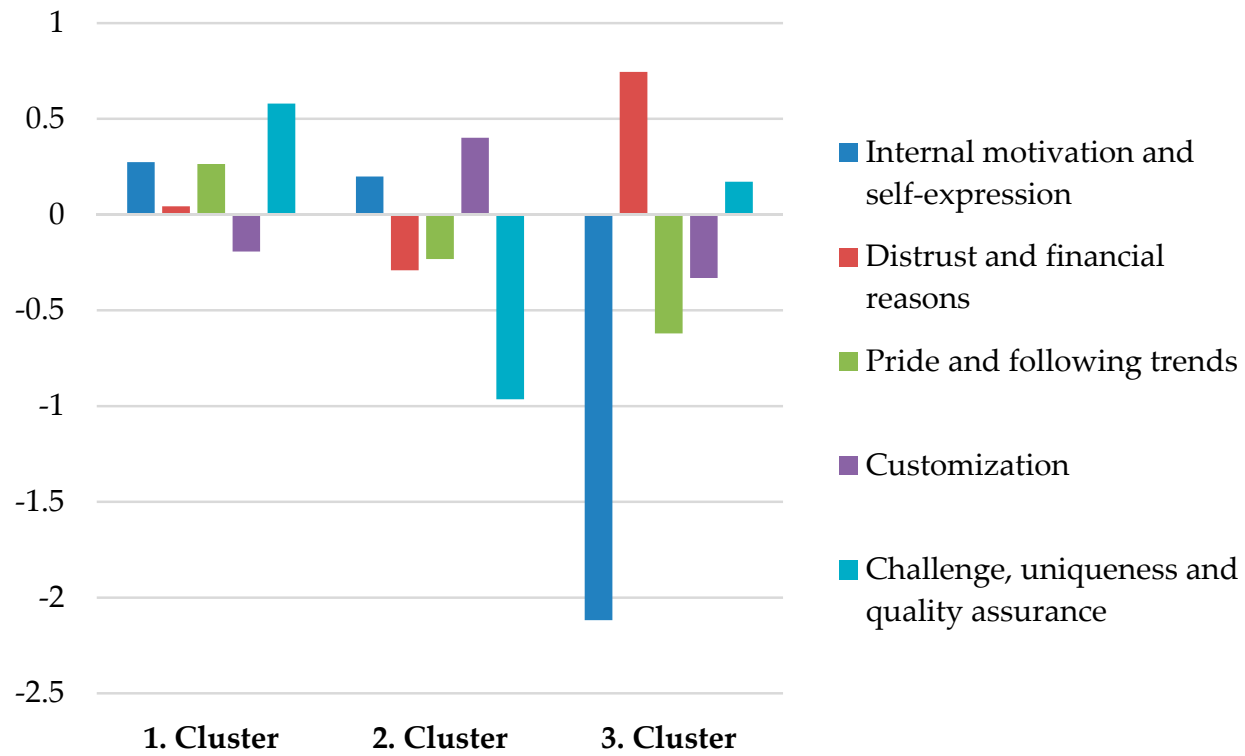

Figure 3. Motivation clusters of DIY activities $(n=270)$; Source: [33].

The first cluster contains 116 respondents, for whom it was very vital to challenge their limits and create unique objects, because this way they will be the only ones owning such products, and they can also be sure about the quality: they can also choose the materials for themselves, the form, and the unique functions. For this group, internal motivation, boasting with the created objects, belonging to a trendy subculture and the joy of self-expression are very important. For the 92 respondents belonging to the second cluster, it was a very significant motivation to create objects according to their own style, which they cannot buy in shops. They can create the objects that are based on their own needs and taste. Internal motivation and self-expressing were not as dominant when compared to the first cluster, but it was still significant. The third cluster contains 62 respondents, and they were those typical DIYers, who are disappointed in the quality and reliability of services provided by professionals, or they just could not find appropriate professionals for their ideas. Therefore, these respondents decided to create objects for themselves, which were observed to be much cheaper and of a much better quality. For them, financial reasons and quality assurance were the main motivations, and their DIY activity was more functional than internal motivation or the tool of self-expression.

Based on these characteristics we named the clusters as follows:

1. Cluster: Self-expression

2. Cluster: Uniqueness-seekers

3. Cluster: Functionalists

The characteristics of clusters are further detailed by the answer package indicated by Table 4 .

The respondents had to evaluate how much they agreed with the questionnaire items provided as to either "I agree with it", "I partly agree with it", "I fully agree with her", or "I disagree". From Table 4, above, the ratio of "I fully agree" and "I disagree" is illustrated in the three clusters. This question although it served as a control question to test cluster test results, but it was also very informative on its own. For $62.1 \%$ of the respondents who belong to the cluster "Self-expression", the DIY activities are a source of joy, which energises and cheers them up, and it also gives them a sense of achievement. The survey found that for a little more than half of the members also find asylum in this activities, which makes them more relaxed in this stressful and uncertain world. When they practice these activities, they can completely "switch off" from the outside world and they can focus on the activity at hand. On the other hand, they can express themselves and their desire to communicate during these handicraft activities, which is the most common for this cluster. The possibility to express themselves is also priority in the case of the "Uniqueness-seekers" cluster; however, it is important for them, due to 
their need to do something unique, to control the activity from the beginning to the end of the project, because this way they can have an experience they cannot get when buying something from shops. For the members of the "Functionalists" cluster, as shown in Table 4, the principle motivation is not necessarily to express one's self or to be unique, but rather the financial reasons. The motivations of the first two clusters' members appear only partly in the third cluster. Most often, they were encouraged to go DIY because professionals lacked or the desire to save money.

Table 4. How much do you agree with the statements about yourself? $(n=270)$.

\begin{tabular}{|c|c|c|c|c|c|c|}
\hline \multirow{3}{*}{ Statement } & \multicolumn{6}{|c|}{ Clusters (\%) } \\
\hline & \multicolumn{2}{|c|}{ 1. Self-Expression } & \multicolumn{2}{|c|}{ 2. Uniqueness-Seekers } & \multicolumn{2}{|c|}{ 3. Functionalists } \\
\hline & $\begin{array}{l}\text { Fully } \\
\text { Agree }\end{array}$ & Disagree & Fully Agree & Disagree & $\begin{array}{l}\text { Fully } \\
\text { Agree }\end{array}$ & Disagree \\
\hline $\begin{array}{l}\text { I often engage in projects such as these, } \\
\text { because I can express myself perfectly through } \\
\text { them and these objects and projects are about } \\
\text { me; they communicate my views }\end{array}$ & 36.2 & 3.4 & 21.7 & 6.5 & 9.7 & 12.9 \\
\hline $\begin{array}{l}\text { Through many of the activities I carry out I } \\
\text { can create a higher quality lifestyle around me }\end{array}$ & 24.1 & 5.2 & 26.1 & 8.7 & 6.5 & 25.8 \\
\hline $\begin{array}{l}\text { I like it very much in these projects, that I } \\
\text { control the whole process, from coming up } \\
\text { with the idea to realising it }\end{array}$ & 44.8 & 1.7 & 37.0 & 13.0 & 6.5 & 45.2 \\
\hline $\begin{array}{l}\text { For me, this is an asylum from the stressful } \\
\text { and uncertain workdays; when I do it, only I } \\
\text { and the activity exist for me, and I enjoy it } \\
\text { very much, it, turns me off" }\end{array}$ & 55.2 & 3.4 & 21.7 & 15.2 & 45.2 & 3.2 \\
\hline $\begin{array}{l}\text { These projects mean a source of joy for me; } \\
\text { they energise and cheer me up, they give me a } \\
\text { sense of achievement }\end{array}$ & 62.1 & 3.4 & 41.3 & 10.9 & 38.7 & 6.5 \\
\hline $\begin{array}{l}\text { Because creativity is very important for me } \\
\text { and I can realise my ideas through it }\end{array}$ & 56.9 & 5.2 & 47.8 & 8.7 & 32.3 & 12.9 \\
\hline $\begin{array}{l}\text { I only work together with friends, } \\
\text { acquaintances or professionals, who I know } \\
\text { and trust. Very often we realise a project in a } \\
\text { creative atmosphere, and we enjoy it } \\
\text { very much }\end{array}$ & 17.2 & 31.0 & 10.9 & 39.1 & 12.9 & 58.1 \\
\hline $\begin{array}{l}\text { I can create an unrepeatable atmosphere, } \\
\text { milieu by the objects I make. This additional } \\
\text { pleasant feeling cannot be bought when } \\
\text { buying something from shops }\end{array}$ & 37.9 & 1.7 & 30.4 & 8.7 & 22.6 & 19.4 \\
\hline
\end{tabular}

Source: [33].

\section{Discussion and Conclusions}

The "DO-IT-YOURSELF" activity is getting increasingly common in Hungary; however, there are not many scientific studies that deal with this subject. Most international literature on this topic focuses on economic/cost cutting consumer motivations, but recently there are an increasing number of studies treating this activity group as a way of sophisticated self-expression. During the research the hypotheses, based on the results of international literature and empirical studies, were assessed by a questionnaire survey amongst a population, which was closely related to DIY, through their activities. The motivation patterns of the Hungarian DIY culture and the presence of international theoretical directions and empirical experience regarding to DIY were investigated by using principle component analysis, cluster analysis, and cross-table analysis.

Hypothesis 1 (H1). The group of DIYers can be described along demographic variables as a homogeneous group.

The current research only partially proved this hypothesis. Although the respondents group can be considered to be homogeneous in terms of educational level and gender distribution (DIY 
activities were most common amongst women with higher education), it was heterogeneous in terms of income status and occupation. A very large percentage of respondents were mothers staying at home with their children, designers, or artists closely related to creativity, but the presence of people working in administrative and less creative workplaces, like pharmacy assistants, bank employees, etc. was also similarly "strong". Overall, the responses revealed that the nature of the work was not highly relevant to the characterization of the group. Cross-tabulation analyses have also demonstrated that, instead of demographic variables, the practice of DIY activities might be linked more to the personality and creativity; so, the group can be more homogeneously described along the common personality traits (the way the individuals live their lives and the values they deem important) than by demographic variables.

Hypothesis 2 (H2). Among the motivations of DIYers the economic one (saving money) is not the most dominant.

The results from questionnaire responses supported primarily inner motivation and self-expression, as well as striving for uniqueness [24-26], active self-realization [1,29-31], and the need for personalization $[28,29]$ and not financial savings $[13,14,16,17]$. These results supported the results of this research hypothesis $(\mathrm{H} 2)$.

Hypothesis 3 (H3). The motivations behind the activities of the DIYers can be characterised as a complex motivational set, in which the individual motivation types are difficult to distinguish, and they complement each other, being related to different fields of life (such as the material sphere, recreation and personality).

The three clusters based on motivations (Self-expression, Uniqueness-seekers, and Functionalists) have confirmed the three main trends in existing literature [21,27]. However, it should be noted that the three clusters were not very distinct from each other, and at a certain level, all three clusters can be characterised by a complex and mixed motivational set. Members of the "Functionalists" cluster [22], Brodersen [21] consider DIY activities primarily as rational and necessary choice and, in the case of the "Uniqueness-seekers" cluster, it can be observed how its members respond to the patterns of media and the society [23]; however, the members of the "Self-expression" cluster completely proved the third direction of the theoretical aspect [24-27] right, which strongly emphasises the symbolic expression of identity.

Answers that were given to close and open questions confirmed the literature findings at several points. The views of the respondents confirmed the empirical presence of the personalization and de-professionalization of Campbell [28]. Analyses by interpretative index categories confirmed the hypothesis that it is difficult to separate one motivational force from the other; in many cases, one catalysing force generates the other, thus a complex multifactorial motivational set dominates the study target group.

Hypothesis 4 (H4). Within the group of DIYers, those individuals will be the majority, who use the activity to express their own inner world, and it is very important for them to make a useful product by themselves, in creative ways.

From the three groups, which were identified by analysing the motivations, in two groups those individuals are dominant, which use DIY activities to express their own inner world, and for whom spending time creatively, making something alone and for themselves, and creating something useful and valuable, is very important. At the same time, for these two clusters, DIY can be interpreted as a distinct personalization and self-expression tool [24-29]. In this interpretation, the DIY activity can be interpreted as an active self-realizing work, in which the creative process is emphasized, together with its completeness and mode. The sociological criticisms that have been expressed regarding to the craft culture $[1,28,30]$ have been proven in the research, especially the members of the of the 
"Self-expression" and "Uniqueness-seekers" clusters, who seek to find their own "oasis" to escape from daily stress and uncertainty and break out from de-professionalization.

These results, because of the intactness of the research topic, were novel, and, naturally, they can be perfect starting points of further studies. With the result of this study-over the importance of DIY activities in sustainability-we suggest differentiating the DIYers, as it is not a homogenous group. From this point of view, DIY could generate various activities from self-sufficiency through economic benefits to community development. Future suggestions may include a deeper and wider analysis of the content of bloggers and their followers through the observation of the business activities of domestic and foreign bloggers targeting the group of DIYers. The research fills a gap in the Hungarian literature. The results other than those that are available in international literature may be considered in defining the direction of further research and in developing theoretical interpretations and models that are related to DIY. These types of activities can be characterized by a increasingly complex set of motivation and, as it is widespread among consumers, it is necessary to examine this type of consumer behavior to be understood. Further deeper vertical research is needed (e.g., in-depth interviews, focus group interviews) to identify the regional-specific DIY culture, the social and economic benefits, and its potentials. We find it important to concentrate on community development and communities of young generations, as DIY can act as a catalyst when it comes to an individual or a community.

Author Contributions: Conceptualization, A.K.-V.; methodology, A.K.-V.; software, A.K.-V. and Z.B.; validation, A.K.-V. formal analysis, A.K.-V.; investigation, Z.B.; resources, A.K.-V. and Z.B.; data curation, A.K.-V.; writing-original draft preparation, A.K.-V. and Z.B.; writing—review and editing A.K.-V. and Z.B.; visualization, A.K.-V. and Z.B.; supervision, A.K.-V. and Z.B. All authors have read and agreed to the published version of the manuscript.

Funding: This research received no external funding.

Conflicts of Interest: The authors declare no conflict of interest.

\section{References}

1. Bourdieu, P. A Társadalmi Egyenlötlenségek Újratermelödése. [Reproduction of Social Inequalities]; Gondolat Publisher: Budapest, Hungary, 1978; p. 436.

2. Baudrillard, J. The Consumer Society: Myths and Structures; Sage Publications: Thousand Oaks, CA, USA; London, UK, 1998; p. 208.

3. Campbell, C. A Modern Fogyasztói Étosz Rejtélye. [The Mystery of Modern Consumer Ethos.]. Replika 1996, VII./21-22, 117-137.

4. Fox, R.W.; Lears Jackson, T.J. The Culture of Consumption: Critical Essays in American History, 1880-1980; Pantheon Books: New York, NY, USA, 1983; p. 236.

5. Vidra, A. A Bevásárlóközpontok Szerepe a Budapesti Fiatalok Szabadidő-Felhasználásában. [The Role of Shopping Centres in the Use of Leisure Time of Youth of Budapest]. Ph.D. Thesis, Debrecen, Hungary, 2006; p. 206.

6. Fodor, E. Az “Élményvámpírok” Hozzák el a Gazdaság új Korszakát LENYÛGÖZÖTT Tömegek. [The "Adventure Vampires" Bring a New Era to the Economy Impressed by the Masses.] HETEK, (XX/34). 2016. Available online: http://www.hetek.hu/eletmod/201608/az_elmenyvampirok_hozzak_el_a_gazdasag_uj_ korszakat (accessed on 16 January 2018).

7. Sipőcz, N. (n.d.): Életmód, Életstílus-Csoportok. Available online: https://erettsegisegedlet.blogspot.hu/2009/ 06/eletmod-eletstilus-csoportok.html (accessed on 16 January 2018).

8. Tier, N.B. (Ed.) A Nagy DIY könyv ... Mire Vársz? [The big DIY book ... . What Are You Waiting for?]; Book Press: Budapest, Hungary, 2015; p. 132.

9. Emilien, G.; Weitkunat, R.; Lüdicke, F. Consumer Perception of Product Risks and Benefits; Springer: Berlin/Heidelberg, Germany, 2017; p. 596.

10. Statista. Value of the DIY market worldwide from 2012 to 2018. 2018. Available online: https://www.statista. com/statistics/374093/global-diy-market-value/ (accessed on 9 December 2019).

11. Statista. Retail Sales of DIY Materials \& Equipment in Hungary 2012-2017. 2018. Available online: https: //www.statista.com/statistics/888122/diy-materials-retail-sales-hungary/ (accessed on 9 December 2019). 
12. Balló, Z. Review of the competition between diy store review of the competition between diy store chains in Hungary. Delhi Bus. Rev. 2010, 11, 13-28.

13. Gelber Steven, M. Do-It-Yourself: Constructing, Repairingand Maintaining Domestic Masculinity. Am. Q. 1997, 49, 66-112. [CrossRef]

14. Williams Colin, C. A Lifestyle Choice? Evaluating the Motives of Do-It-Yourself (DIY) Consumers. Int. J. Retail Distrib. Manag. 2004, 32, 270-278. [CrossRef]

15. Wolf, M.; McQuitty, S. Circumventing Traditional Markets: An Empirical Study of the Marketplace Motivations and Outcomes of Consumers' Do-It-Yourself Behaviors. J. Mark. Theory Pract. 2013, 21, 195-209. [CrossRef]

16. Bateson John, E.G. Self-Service Consumer: An Exploratory Study. J. Retail. 1985, 61, 49-76.

17. Dabholkar, P. Consumer Evaluations of New Technology-Based Self-Service Options. Int. J. Res. Mark. 1996, 13, 29-51. [CrossRef]

18. Wolf, M.; McQuitty, S. Understanding the Do-it-Yourself Consumer: DIY Motivations and Outcomes. Acad. Mark. Sci. Rev. 2013, 1, 154-170. [CrossRef]

19. Lowndes, S. The DIY Movement in Art, Music and Publishing: Subjugated Knowledges (Do-It-Yourself Movement in Art, Music and Publishing); Series: Routledge Research in Cultural and Media Studies; Routledge: New York, NY, USA, 2016; p. 87.

20. Bennett, A.; Guerra, P. DIY Cultures and Underground Music Scenes. Abingdon, Oxon; Routledge: New York, NY, USA, 2019; p. 315.

21. Brodersen, S. Do-It-Yourself Work in North-Western Europe: Maintenance and Improvement of Homes; Rockwool Foundation: Copenhagen, Denmark, 2003; p. 129.

22. Littlewood, A.; Munro, M. Explaining disrepair: Examining owner occupiers' repair and maintenance behaviour. Hous. Stud. 1996, 11, 503-525. [CrossRef]

23. Mintel. DIY Review 2005; Mintel: London, UK, 2005.

24. Crewe, L. Geographies of retailing and consumption. Prog. Hum. Geogr. 2000, 24, 275. [CrossRef]

25. Dowling, A. Femininity, place and commodities: A retail case study. Antipode 1993, 25, 295-319. [CrossRef]

26. Woodward, I. Divergent narratives in the imagining of the home amongst middle-class consumers; aesthetics, comfort and the symbolic boundaries of self and home. Sociology 2003, 39, 391-412.

27. Clarke, A. The Aesthetics of Social Aspiration; Miller, D., Ed.; Home Possessions; Berg: Oxford, UK, 2001.

28. Campbell, C. The craft consumer: Culture, craft and consumption in a postmodern society. J. Consum. Cult. 2005, 5, 23-42. [CrossRef]

29. Miller, D. Material Culture and Mass Consumption; Blackwell: Oxford, UK, 1987; p. 252.

30. Holt, D. Distinction in America? Recovering Bourdieu's theory of taste from its critics. Poetics 1997, 25, 93-120. [CrossRef]

31. Bakos, I.M. Local Food Systems Supported by Communities Nationally and Internationally. Deturope 2017, 9 , 59-79.

32. Sikos, T.T. Marketingföldrajz. [Marketing Geography]; VÁTI Kht. Publisher: Budapest, Hungary, 2000; p. 240.

33. Khademi-Vidra, A. Research Data as Analyzed Using Data Analysis Software; SPSS, Excel; Szent István University: Gödöllő, Hungary, 2017.

34. Sajtos, L.; Mitev, A. SPSS kutatási és Adatelemzési Kézikönyv. [SPSS Research and Data Analysis Handbook]; Alinea Publisher: Budapest, Hungary, 2007; p. 404.

35. Mason, J. Kvalitatív Kutatás. [Qualitative Research]; Jószöveg Múhely Publisher: Budapest, Hungary, 2005; p. 208.

(C) 2020 by the authors. Licensee MDPI, Basel, Switzerland. This article is an open access article distributed under the terms and conditions of the Creative Commons Attribution (CC BY) license (http://creativecommons.org/licenses/by/4.0/). 